\title{
DE LAS ARMAS AL PARLAMENTO. LOS ORÍGENES DE EUSKADIKO EZKERRA (1976-1977) ${ }^{1}$
}

\author{
Gaizka Fernández Soldevilla
}

\section{Introducción}

La mayoría de los investigadores del nacionalismo vasco se han centrado en sus organizaciones más representativas (PNV y ETA), olvidando a otros grupos, como Euskadiko Ezkerra (Izquierda de Euskadi), cuya historia «está por escribir» ${ }^{2}$. EE apareció como candidatura en 1977 y hasta 1982 fue la plataforma electoral de EIA, Euskal Iraultzarako Alderdia (Partido para la Revolución Vasca), el partido creado por ETApm (ETA político-militar). En 1982 EIA convergió con el sector mayoritario del Partido Comunista de Euskadi para dar lugar a Euskadiko Ezkerra-Izquierda para el Socialismo, la mejor representación de lo que el profesor José Luis de la Granja ha denominado «nacionalismo vasco heterodoxo» (moderado, integrador y autonomista), cuyo antecedente fue Acción Nacionalista Vasca (ANV) durante los años 30 del siglo XX ${ }^{3}$. La existencia de EE terminó en 1993 con su fusión con el Partido Socialista de Euskadi para formar el PSE-EE. El objetivo de este artículo es explicar la parte menos conocida de esta historia, esto es, los orígenes de Euskadiko Ezkerra.

1. El autor agradece a José Luis de la Granja Sainz, Raúl López Romo, Anabel Hernández Álvarez y Elvira Salaverri sus valiosas sugerencias para mejorar el texto original.

2. Granja, José Luis de la, Beramendi, Justo y Anguera, Pere, La España de los nacionalismos y las autonomías, Madrid, 2001, p. 189.

3. Granja, José Luis de la, El siglo de Euskadi. El nacionalismo vasco en la España del siglo XX, Madrid, 2003, p. 51. 
El texto se enmarca en la Historia Actual, que comienza a ser objeto de estudio de la nueva generación de historiadores del País Vasco ${ }^{4}$. Ya se ha escrito con detenimiento sobre la Historia del Presente ${ }^{5}$, pero conviene recordar que plantea importantes dificultades al investigador, como, por ejemplo, la ausencia de obras especializadas o la imposibilidad de consultar ciertos archivos, por no hablar, en el caso específico vasco, de que el convulso pasado reciente permanece en el centro del debate político hoy en día 6 . Sin embargo, también ofrece otros recursos, como son los archivos personales y las fuentes orales, que han sido aprovechados en esta investigación ${ }^{7}$.

En sus orígenes ETApm, EIA y EE formaban parte de la izquierda abertzale ${ }^{8}$, cuyo pasado no puede explicarse atendiendo sólo a las claves político-ideológicas habituales, ya que ha terminado formando una «religión de sustitución» ${ }^{9}$ o, mejor, una «religión política» que el profesor Jesús Casquete ha denominado «gudarismo» ${ }^{10}$. Por eso, el historiador necesita enriquecer su punto de vista con el de la historia cultural, concretamente con el estudio del universo simbólico del nacionalismo radical (héroes, mártires, ritos, etc.), elementos indispensables para suscitar las adhesiones emocionales (casi religiosas) que crearon la identidad colectiva abertzale. Por tanto, el simbolismo se emplea como complemento del hilo principal, que es el relato histórico.

\section{ETA al final del franquismo}

Durante los últimos años de la dictadura ETA inició una escalada de atentados sin precedentes. En 1973 ETA asesinó al presidente del Gobierno Carrero Blanco

4. López Romo, Raúl, Del gueto a la calle. El movimiento gay y lesbiano en el País Vasco y Navarra, 1975-1983, San Sebastián, 2008; CARNICERo, Carlos, La ciudad donde nunca pasa nada: Vitoria, 3 de marzo de 1976, Vitoria, 2007.

5. Aróstegui, Julio, La historia vivida. Sobre la historia del presente, Madrid, 2004.

6. Montero, Manuel, «El concepto de Transición en el País Vasco», Studia historica. Historia Contemporánea, vol. 22 (2004), pp. 247-267.

7. Si no se consigna lo contrario, tanto las publicaciones como el resto de documentos utilizados pertenecen al archivo personal del autor, formado por préstamos de ex militantes de ETApm, EIA y EE como Kepa Aulestia, Ángel Toña, Enrique Urkijo, Iñaki Maneros, Josetxo Álvarez, Mikel Unzalu, etc.

8. Utilizo «izquierda abertzale» y «nacionalismo vasco radical» como sinónimos, aunque en sentido estricto la izquierda abertzale, caracterizada por sus posiciones más o menos socialistas y su vinculación con ETA, es un subgrupo dentro del segundo.

9. Sáez de la Fuente, Izaskun, El Movimiento de Liberación Nacional Vasco, una religión de sustitución. Bilbao, 2002.

10. Casquete, Jesús, En el nombre de Euskal Herria. La religión política del nacionalismo vasco radical, Madrid, 2009 
y en 1974 a otras diecinueve personas ${ }^{11}$. El crecimiento de su efectividad y la represión torpe e indiscriminada con la que reaccionó la dictadura dispararon su popularidad y su prestigio entre la oposición antifranquista, de la que se convirtió en uno de los principales referentes. A pesar de ello, paralelamente renacían las disensiones internas en ETA debido al protagonismo del Frente Militar. Un sector del Frente Obrero, que denunció haber sido relegado a una simple oficina de reclutamiento para el Militar, decidió escindirse en 1974 y formar el partido LAIA, Langile Abertzale Iraultzaileen Alderdia (Partido de los Trabajadores Patriotas Revolucionarios) $)^{12}$.

El 13 de septiembre de 1974 ETA asesinaba a trece personas y hería a ochenta en un atentado en la cafetería Rolando (Madrid). El objetivo era la policía, pero las víctimas fueron civiles. Se discutió si asumir o no la responsabilidad. El Frente Militar, en el que se encuadraban los autores del atentado, intentó que ETA lo reivindicase, pero la dirección se opuso por considerarlo contraproducente. Como respuesta, los «militares» se negaron a aceptar las directrices del Ejecutivo y crearon su propia organización ${ }^{13}$. Fue conocida desde entonces como ETAm (ETA militar), mientras que la mayoría alienada con la dirección pasó a denominarse ETApm. El atentado fue sólo el detonante, ya que las causas de la ruptura eran anteriores. Según el profesor Gurutz Jáuregui, se trataba del sempiterno debate sobre cómo coordinar terrorismo y política ${ }^{14}$.

Por un lado, quedó ETAm, liderada por José Miguel Beñaran (Argala), que defendió que ETA debía convertirse en «la vanguardia revolucionaria» dedicada exclusivamente a la «lucha armada» y automarginada de la lucha política ${ }^{15}$. Para los milis sólo así se podía lograr proteger a los partidos de la izquierda abertzale de la represión y a ETAm de una posible contaminación «reformista» proveniente de éstos ${ }^{16}$.

Esa idea de separar lo «político» y lo «militar» fue fundamental para la aparición ese mismo año de un pequeño grupo que dio lugar a EHAS, Euskal Herriko Alderdi Sozialista (Partido Socialista de Euskal Herria), el segundo partido de la

11. Pulgar, María Belén, «Víctimas del terrorismo», Asociación de Víctimas del Terrorismo, <http://www.avt.org/victimas/1968-1977.pdf>.

12. «La práctica de ETA en los últimos años», Sugarra, 1 (1975).

13. «Historia organizativa desde la escisión del Frente Obrero hasta la 2. ${ }^{a}$ parte de la VI Asamblea», Documentos Y, San Sebastián, vol. XVII (1979), pp. 249-257. Para simplificar se obviará lugar y año para Documentos $Y$.

14. Jáuregui, Gurutz, «ETA: Orígenes y evolución ideológica y política», en Elorza, Antonio (dir.), Historia de ETA, Madrid, 2006, p. 256.

15. «ETAren Agiria», 1974.

16. «Relación actividad de masas-actividad armada», Documentos Y, vol. XVIII, pp. 189-196. 
izquierda abertzale ${ }^{17}$. En 1977, tras converger con Eusko Sozialistak (Socialistas Vascos) e independientes, pasó a denominarse HASI, Herriko Alderdi Sozialista Iraultzailea (Partido Socialista Revolucionario del Pueblo) ${ }^{18}$, posteriormente núcleo de la futura Herri Batasuna.

Por el otro lado, la dirección de ETApm apostó por dotarse de una estructura político-militar que fuese capaz de hacer compatibles la «lucha armada» y la lucha política ${ }^{19}$. Para intentar evitar una nueva deriva autónoma del Frente Militar, se decidió «politizar el aparato militar» y crear los Komando Bereziak

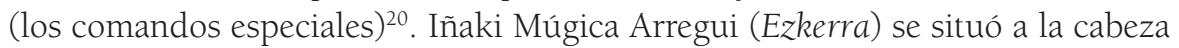
de ETApm, Pedro Ignacio Pérez Beotegui (Wilson) a la de los berezis y Eduardo Moreno Bergaretxe (Pertur) a la de la Oficina Política.

Sin embargo, la estrategia político-militar no dio los resultados esperados. Las huelgas convocadas por los polimilis lograron un escaso seguimiento, lo que contrastaba con el éxito de las de la extrema izquierda, como la del 11 de diciembre de 1974, organizada por el MCE (Movimiento Comunista de España) ${ }^{21}$, proveniente de la primera escisión no nacionalista de ETA.

ETApm no supo evitar verse arrastrada por la inercia de su antecesora y en 1975 puso en marcha una gran campaña terrorista. El año acabó con dieciséis víctimas mortales causadas por las dos ETA. Pero esta vez el Gobierno había aprendido de sus errores ${ }^{22}$. Además de responder con un estado de excepción y un decreto-ley antiterrorista, el SECED (Servicio Central de Documentación), el servicio secreto, había conseguido infiltrar a un topo en ETApm: Mikel Lejarza $(\text { Lobo })^{23}$. La actuación de Lobo permitió a la policía arrestar en julio de 1975 a 145 polimilis, incluyendo a Ezkerra y a Wilson ${ }^{24}$. A pesar de las múltiples protestas en España y el resto de Europa ${ }^{25}$, dos de los detenidos (Juan Paredes, Txiki, y Ángel Otaegi) fueron ejecutados junto a tres militantes del FRAP el 27 de sep-

17. Entrevista a Joseba Agirreazkuenaga, Lejona, 7 de julio de 2008.

18. Véase Arregr, Natxo, Memorias del KAS (1975-1978), San Sebastián, 1981.

19. «¿Por qué defendemos una estructura político-militar?», Kemen, 4 (octubre 1974).

20. «Resolución sobre el FM», Kemen, 2 (1974), en Documentos Y, vol. XV, p. 303.

21. Ibarra Güell, Pedro y García Marroquín, Chelo, «De la primavera de 1956 a Lejona 1978. Comisiones Obreras de Euskadi», en Ruzz, David (dir.), Historia de Comisiones Obreras, Madrid, 1993, pp. 133 y 134.

22. Casanellas, Pau, «Los últimos zarpazos del franquismo: el decreto-ley sobre prevención del terrorismo de agosto de 1975», Historia del Presente, 12 (2008), pp. 155-172.

23. VInADER, Xavier, Operación Lobo. Memorias de un infiltrado en ETA, Madrid, 1999.

24. Díaz Fernández, Antonio M., Los servicios de inteligencia españoles. Desde la guerra civil hasta el 11-M. Historia de una transición, Madrid, 2005, p. 173.

25. Véase la multitud de noticias al respecto en Mundo Obrero, 27 (2. ${ }^{a}$ semana, septiembre 1975); Mundo Obrero, 29 (4. ${ }^{a}$ semana, septiembre 1975); El Socialista, 47 (1. ${ }^{\text {a }}$ quincena septiembre 1975); Servir al pueblo, 43 (septiembre 1975). 
tiembre de ese año, convirtiéndose en los mártires de ETApm ${ }^{26}$. Desde entonces, al principio con actos unitarios, la izquierda abertzale conmemoró ritualmente el día de su fusilamiento ${ }^{27}$.

\section{La renovación teórica de Pertur}

La operación Lobo dejó a ETApm en una situación crítica, con sólo un comando activo y sus máximos dirigentes encarcelados. El Comité Ejecutivo tuvo que ser renovado con, entre otros, Javier Garayalde (Erreka), Martín Auzmendi (Irrati) y Miguel Ángel Apalategui (Apala), que se puso al frente de los Komando Bereziak.

Pertur era el dirigente político de ETApm más significativo. Se declaraba «comunista abertzale» ${ }^{28}$, aunque no tomaba el marxismo-leninismo como un dogma y su nacionalismo tenía rasgos heterodoxos. Por ejemplo, cuando en octubre de 1972 intervino por primera vez ante la cúpula de ETA, Pertur tocó con su guitarra el Eusko Gudariak («Soldados vascos», quizá el más simbólico himno de la izquierda abertzale) «en versión flamenca. No tuvo el éxito esperado y decidió replegarse discretamente» ${ }^{29}$.

Pertur comprendió que se iba a implantar en España una democracia parlamentaria y que en ese sistema las limitaciones de la estructura y la estrategia de ETApm le iban a impedir competir en igualdad de condiciones con el PNV y el $\mathrm{PSOE}^{30}$. O la izquierda abertzale evolucionaba o desaparecía. Ayudado por algunos colaboradores como Irrati y Erreka, Pertur intentó adaptar su organización al cambio que se avecinaba.

En primer lugar, impulsó la creación de organizaciones de masas «autónomas» (en realidad correas de transmisión de ETApm) que pudiesen competir con las del PCE y la extrema izquierda. La más importante y duradera fue el sindicato LAB, Langile Abertzaleen Batzordeak (Comisiones de Obreros Patriotas) ${ }^{31}$.

En segundo lugar, Pertur propuso en la Ponencia Otsagabia cambiar de estrategia y desdoblar ETApm en dos nuevas organizaciones con tareas especializadas. Por un lado, un partido obrero que, siguiendo el modelo bolchevique, se erigiese en la «dirección política del proceso revolucionario vasco» y que aprovechase «todos los cauces» de la «democracia burguesa», incluyendo las elecciones

26. Sánchez Erauskin, Javier, Txiki-Otaegi: El viento y las raíces, San Sebastián, 1978.

27. «Al pueblo de Euskadi», septiembre de 1976, ArChivo del Gobierno Civil DE VizCAya (AGCV); «Editorial», Bultzaka, 1 (octubre 1977); «27 de septiembre», Bultzaka, 12 (27 octubre 1978).

28. Cit. en Amigo, Ángel, Pertur. ETA 71-76, San Sebastián, 1978, p. 225.

29. Ibidem, p. 40.

30. «A la izquierda vasca», Langile, n. $^{\circ} 2$.

31. «Tesis sobre LAB», Kemen, 6 (agosto 1975). 
(«hay que participar, es evidente, hay que intentar ganar»). Por otro, una nueva ETApm que se dedicase a la «lucha armada» adoptando el papel de retaguardia, es decir, defensa de las conquistas políticas del partido ${ }^{32}$.

La Ponencia Otsagabia, que fue aprobada en la VII Asamblea de ETApm en septiembre de $1976^{33}$, suponía aceptar que iba a haber un cambio político real en España, que había que participar en él, y que esa participación debía estar guiada no por ETApm sino por el partido ${ }^{34}$. En cierto sentido, las ideas de Pertur anunciaban gran parte de la evolución de EIA y EE, así como la posibilidad de que algún día, tal y como sucedió en 1982, el partido propiciase el fin de la organización terrorista.

ETAm apoyó explícitamente el plan de Pertur, ya que Argala creía que ETApm iba a convertirse en un partido político y que sus restos iban a reunificarse con ETAm para dar lugar a una única organización ${ }^{35}$. Desde octubre de 1976 hubo tres reuniones bilaterales para tratar el tema de una posible reunificación, pero no se llegó a nada por falta de voluntad real ${ }^{36}$.

La tercera innovación de Pertur fue defender la alianza del nacionalismo radical con la extrema izquierda no nacionalista (los hasta entonces «traidores» y «españolistas»). La izquierda abertzale había demostrado no estar preparada para la lucha política, por lo que necesitaba a quien sí lo estaba. Preocupado por la aparición de organismos unitarios antifranquistas, Pertur propuso que ETApm formase una alianza estratégica con el resto de la izquierda abertzale y una alianza táctica con la extrema izquierda ${ }^{37}$.

En el verano de 1975 surgió KAS, Koordinadora Abertzale Sozialista (Coordinadora Patriota Socialista) que se definió como «coordinadora consultiva» y «mesa permanente de debate» del nacionalismo radical ${ }^{38}$. El 18 de agosto de 1976 KAS se formalizó con la firma de un manifiesto en el que exponía su alternativa táctica para «Euskadi sur» (libertades democráticas, amnistía, disolución de los «cuerpos represivos», reconocimiento del derecho de autodeterminación, autonomía provisional, bilingüismo y mejora de condiciones laborales y de vida ${ }^{39}$.

32. Otsagabia, «El Partido de los Trabajadores Vascos: una necesidad urgente en la coyuntura actual» y «ETA y la lucha armada», 7 de julio de 1976.

33. «A todo el Pueblo Vasco. Manifiesto del VII. Biltzar Nagusia de ETA», Documentos Y, vol. XVIII, pp. 238-247.

34. Entrevista a Javier Garayalde, Vitoria, 6 de febrero de 2007.

35. «Sobre la evolución de la organización político-militar», Zutik, 67 (noviembre 1976).

36. Entrevista a Joseba Aulestia, Bilbao, 19 de febrero de 2007.

37. «A la izquierda vasca», Langile, n. ${ }^{\circ} 2$.

38. «Comunicado de fundación del KAS», 1 de agosto de 1975, en Documentos Y, vol. XVII, p. 483.

39. «Manifiesto y alternativa del KAS», 1976. 
La alianza táctica con la extrema izquierda se concretó en dos efímeros frentes antifranquistas: el EHB, Euskadiko Herrikoi Batzarra (Asamblea Popular de Euskadi), nacido a finales de $1975^{40}$ y desaparecido unos meses después por la hostilidad de ETAm y LAIA ${ }^{41}$, y el EEH, Euskal Erakunde Herritarra (Organismo Popular Vasco), surgido en septiembre de 1976, que únicamente consiguió la firma de un programa común ${ }^{42}$.

\section{Esta dinámica infernal}

Las ideas de Pertur encontraron la constante obstrucción de los berezis. Éstos, nacionalistas a secas y militaristas a ultranza, consideraban que la Ponencia Otsagabia iba a conducir a «la desaparición de ETA en la práctica» ${ }^{43}$. Paralelamente, el poder y autonomía de los berezis aumentaba peligrosamente. Para financiar su reconstrucción organizativa ETApm había empezado a extorsionar con el «impuesto revolucionario» y a recurrir al secuestro. Los berezis, sin conocimiento de la dirección polimili, secuestraron en 1976 a los empresarios José Luis Arrasate y Ángel Berazadi. Este último, a pesar de la oposición de Pertur y sus colaboradores, fue asesinado al no satisfacer parte del dinero exigido ${ }^{44}$. Una vez más surgía el problema de la deriva autónoma del Frente Militar.

ETApm se dividió en dos facciones: la mayoría, que seguía las ideas de Pertur, y los berezis, que veían cualquier cambio como una traición ${ }^{45}$. A finales de abril de 1976 estos últimos acusaron a Pertur de haberse saltado las normas de seguridad y le secuestraron para juzgarlo ellos mismos y ejecutar luego la sentencia que decidieran ${ }^{46}$. El resto de ETApm les obligó a soltarlo, pero la tensa situación interna se había deteriorado hasta tal punto que en una carta a su familia Pertur describía ETApm como un «estado policial donde cada uno sospecha del vecino y éste del otro (...). No logro zafarme de esta dinámica infernal de las conspiraciones, del infundio, de la mentira, etc. ${ }^{47}$.

El 23 de julio de 1976 Pertur tenía una misteriosa cita en San Juan de Luz. Según la versión de los berezis Apala y Francisco Mujika Garmendia (Pakito), los

40. «Acta de la Reunión en Biarritz», en Documentos Y, vol. XVII, pp. 411-415.

41. «La supuesta alternativa unitaria entre fuerzas españolistas y fuerzas abertzales socialistas», Zutik, 66 (marzo 1976).

42. «Izquierda vasca unidad», Punto y Hora de Euskal Herria, 23 (17-23 febrero 1977).

43. «Ponencia retirada en el VII BN», en Documentos Y, vol. XVIII, pp. 207-219.

44. Amigo, Ángel, Pertur..., pp. 125-126.

45. Entrevista a Javier Garayalde, cit.

46. «Informe sobre la Conferencia de Cuadros», mayo de 1976, en Documentos Y, vol. XVIII, pp. 30-47.

47. «Pertur: ¿Quién está detrás?», Punto y Hora de Euskal Herria, 72 (26 enero - 1 febrero 1978). 
últimos con los que se le vio en público ${ }^{48}$, Pertur les pidió que le llevaran en coche hasta un determinado punto, donde le dejaron. Nunca más se supo de él.

ETApm y la familia de Pertur acusaron de su desaparición a grupos terroristas de extrema derecha ${ }^{49}$. Tras hacerse pública la noticia, tres organizaciones diferentes reivindicaron su asesinato, sin dar a conocer el paradero del cadáver. Pero pronto surgió la hipótesis de que los propios berezis habían asesinado a Pertur, versión que tanto ETApm como la familia de Pertur apoyó desde entonces ${ }^{50}$. De cualquier manera, la figura de Pertur se convirtió en el principal icono de referencia y movilización de ETApm y EIA, en cuyos actos aparecía siempre un cartel con su efigie. Pertur aunaba la triple imagen de héroe, mártir y fundador de EIA y $E^{51}$, y su memoria fue conmemorada ritualmente hasta el fin de $\mathrm{EIA}^{52}$. Su caso es comparable al de Argala, asesinado simbólicamente el 21 de diciembre de 1978 (cinco años y un día después del atentado mortal contra Carrero Blanco, en el que había participado) y convertido desde entonces en el héroe-mártir por excelencia de ETAm $^{53}$.

\section{El novedoso arte del diálogo}

Desde la muerte de Franco se sucedieron en España dos años convulsos en los que el fin del régimen no estaba claro, como demostraron la frustración del tímido aperturismo del gobierno Arias Navarro, los excesos de las fuerzas de orden público y la actuación del terrorismo de extrema derecha ${ }^{54}$. Cuando Adolfo Suárez accedió a la Presidencia la democratización cobró un impulso real. El presidente comenzó a reunirse con miembros de la oposición moderada e hizo algunos gestos sobre asuntos básicos como el de los presos políticos: la Ley de

48. «El exiliado que vio a "Pertur" por última vez con vida confirma que estaba con "Apala" y "Pakito"», El Correo, 28 de noviembre de 2008.

49. «Denuncia presentada al juzgado de instrucción de guardia de San Sebastián por Álvaro y Marta Moreno Bergareche», julio de 1976. Centro de Documentación de Historia Contemporánea de la Sociedad de Estudios Vascos (CDC), Caja Gestoras pro-Amnistía (19731978).

50. «La familia de "Pertur" acusa a ETA de su desaparición», El País, 21 de enero de 1978. El caso Pertur sigue abierto hoy en día, sin que se haya podido descartar ninguna de las autorías posibles.

51. Askatasuna, 73 (3 agosto 1976); Hautsi, número especial Pertur, 23 de julio de 1978.

52. «Los etarras extrañados comparecen ante veinte mil personas durante un acto en memoria de "Pertur"», El País, 30 de julio de 1977; «Pertur hoy», Bultzaka, 10 (21 junio 1978); «Omenaldia», Hitz, 1 (julio 1979); «Omenaldi», Hitz, 13 (verano 1981).

53. Casquete, Jesús, «Agitando emociones. La apoteosis del héroe-mártir en el nacionalismo vasco radical», Cuadernos Bakeaz, 81 (2007).

54. Sartorius, Nicolás y SABIO, Alberto, El final de la Dictadura. La conquista de la democracia en España (noviembre de 1975-junio de 1977), Madrid, 2007, pp. 253-416. 
Amnistía del 30 de julio de 1976, posteriormente ampliada con el Real DecretoLey del 14 de marzo de $1977^{55}$.

Sin embargo, las medidas de excarcelación no afectaron a la mayoría de los presos de ETA, que se habían convertido en un símbolo antifranquista de primer $\operatorname{orden}^{56}$. Las organizaciones de la izquierda abertzale y las de extrema izquierda, que no habían sido legalizadas, adoptaron como objetivo básico conseguir una amnistía general ${ }^{57}$. Fue ésta, junto a la exigencia de legalización de todos los partidos y de un estatuto de autonomía, la principal consigna movilizadora de la multitud de manifestaciones que hubo en esos años. Si a éstas se les suman los conflictos laborales, las continuas huelgas, los excesos de las Fuerzas de Orden Público, los atentados terroristas tanto de ETA como de los «incontrolados» ${ }^{58}$, el resultado era una situación tan convulsa que el profesor Juan Pablo Fusi la ha descrito como «una pesadilla» ${ }^{59}$. Un buen ejemplo de la inestabilidad política en el País Vasco fue la primera huelga en memoria de Txiki y Otaegi el 27 de septiembre de 1976, en la que se reclamaba la amnistía. Unos días antes la Jefatura Superior de Policía de Bilbao informaba de un ambiente de «psicosis política y social» y de que la situación aparentaba la de una «pre-dictadura roja $»^{60}$ y después de la jornada tuvo que admitir que había perdido el control de la calle y las fábricas, ya que cuando las fuerzas de oposición:

«pretenden paralizar la vida de esta región policial, lo consiguen fácilmente con sólo buscar algún pretexto idóneo, sin que haya fuerza posible dentro del entorno laboral que pueda frenar esta forma de subversión, que a no dudarlo será aplicada en cualquier momento que deseen un golpe de fuerza contra el Gobierno de la Nación» ${ }^{61}$.

55. Aguilar Fernández, Pilar, «La amnesia y la memoria: las movilizaciones por la amnistía en la Transición a la Democracia», en Cruz, Rafael y Pérez Ledesma, Manuel (eds.), Cultura y movilización en la España Contemporánea, Madrid, 1997, pp. 327-357.

56. Los presos de ETA eran auténticos mitos vivientes. No sólo eran recibidos en masivas manifestaciones como héroes, sino que en la izquierda abertzale se les consideraba los líderes naturales del colectivo. Así, cuando Mario Onaindía, el más prestigioso condenado del proceso de Burgos, regresó al País Vasco tras ocho años de cárcel y una breve estancia en el exilio, hubo consenso en nombrarle secretario general de EIA. Entrevista a Iñaki Albistur, San Sebastián, 10 de enero de 2009.

57. «Indulto = nuevo engaño para Euskadi», 1976, AGCV.

58. Pérez Pérez, José Antonio y Carnicero Herreros, Carlos, «La radicalización de la violencia política durante la Transición en el País Vasco. Los años de plomo», Historia del Presente, 12 (2008), pp. 111-128.

59. Fusi, Juan Pablo, El País Vasco. Pluralismo y nacionalidad, Madrid, 1984, p. 178.

60. «Boletín informativo semanal regional», Bilbao, del 18 al 25 de septiembre de 1976. AGCV.

61. «Boletín informativo semanal regional», Bilbao, del 26 de septiembre al 1 de octubre de 1976. AGCV. 
Era evidente que si ese mismo Gobierno deseaba llevar a buen puerto la Transición no podía obviar este grave problema, aunque tampoco podía obviar la presión en sentido opuesto de los denominados «poderes fácticos», especialmente el Ejército.

En ese contexto hay que situar los tres contactos que ETApm mantuvo con delegados de Suárez desde noviembre de 1976 hasta mediados de 1977. A los encuentros iniciales, que se produjeron en Ginebra (Suiza), acudieron por parte de ETApm Erreka y Jesús María Muñoa (Txaflis) y por parte del Gobierno el comandante Ángel Ugarte del SECED. En el único en el que ETAm participó, el de diciembre, su papel se limitó a comunicar «que no teníamos nada de que hablar» ${ }^{62}$. Tampoco el resto de KAS quiso saber nada de diálogo ${ }^{63}$.

Se trató de la primera vez en la historia en que ETA dialogaba con un Gobierno español (en términos simbólicos, con el antihéroe). Los encuentros habían surgido de una confluencia temporal de intereses. Por una parte, ETApm necesitaba conseguir tanto la tolerancia del Gobierno hacia el nuevo partido como una amnistía que satisficiese a sus seguidores ${ }^{64}$. Por otra, el Gobierno quería que las primeras elecciones no se vieran empañadas por el terrorismo y explorar la posibilidad de que ETA apostase por la vía institucional. Según Ugarte, Suárez le ordenó que intentase «sacarles una tregua» y que les insinuase «la posibilidad de una amnistía más amplia» ${ }^{65}$.

Pero ni el Gobierno consiguió una tregua, ni ETApm una amnistía general. Según Erreka, sólo fueron «sondeos, intentos de tomar la temperatura», en los que ETApm dejó claro que «si querían unas elecciones democráticas pacíficas, la condición sine qua non era que salieran los presos» ${ }^{66}$. Si ETApm mantuvo una «tregua de hecho» fue porque era una «tregua técnica, un parón», debido a los problemas derivados del desdoblamiento y no a una decisión política ${ }^{67}$. Precisamente, la crisis de ETApm estalló cuando una parte de su dirección propuso declarar oficialmente una tregua ${ }^{68}$.

Esta propuesta, que no se hizo pública, fue la excusa de los berezis para intentar dar un golpe de fuerza en ETApm. La razón de fondo era que los Komando Bereziak no aceptaban las ideas de Pertur, por lo que acusaban a la dirección

62. «Sobre la ejecución de Ibarra», Zutik, 68 (julio 1977).

63. Ugarte, Ángel y Medina, Francisco, Espía en el País Vasco, Barcelona, 2005, pp. 244 y 245.

64. Entrevista a Javier Garayalde, cit.

65. Ugarte, Ángel y Medina, Francisco, Espía en..., pp. 217-219.

66. Entrevista a Javier Garayalde, cit.

67. Entrevista a Joseba Aulestia, cit.

68. «Propuesta de declaración del BT. Explicación de la propuesta», Kemen, 11 (abril 1977). 
polimili de traición y liquidacionismo de «la lucha armada $»^{69}$. Los berezis montaron una organización paralela que declaró ser la auténtica ETApm e invitaron al resto de los polimilis a unirse a ellos. Sin embargo, la mayoría se mantuvo fiel a la dirección ${ }^{70}$. La existencia de los Komando Bereziak como organización autónoma era inviable. Un sector se unió a otros grupos heterogéneos para formar los CAA (Comandos Autónomos Anticapitalistas) $)^{71}$, mientras que la mayor parte de los berezis, tras asesinar al empresario y político franquista Javier de Ybarra el 22 de junio de 1977, se unieron a ETAm en septiembre de ese año ${ }^{72}$.

EIA heredó los contactos con Ugarte. El comandante estaba empeñado en propiciar el nacimiento del partido para debilitar a ETApm ${ }^{73}$, EIA en aprovechar las ventajas que se le ofrecían. Iñaki Martínez, el delegado del partido, pidió «una prueba de buena voluntad en cuanto a la posibilidad de participar en las elecciones» a lo que Ugarte le transmitió que «se podrá presentar cualquiera». En ese momento la dirección provisional de EIA dudaba, aunque se mantenía a la expectativa. "Nuestra sorpresa fue mayúscula cuando Suárez nos dijo, por medio de Ugarte, que podíamos ir organizando la presentación de Gallarta que no la iban a prohibir, como así fue» ${ }^{74}$. Tanto la tolerancia a la actividad pública de EIA, un partido ilegal, como el extrañamiento (expulsión al extranjero) de algunos de los más importantes presos de ETA en mayo de 1977 fueron fundamentales para que la mayoría de la dirección del partido consiguiese imponer sus tesis a favor de la participación en las elecciones.

\section{El Partido para la Revolución Vasca}

Tras su VII Asamblea (1976), ETApm llevó a cabo dos procesos conocidos como desdoblamiento y reagrupamiento. El desdoblamiento fue la división de ETApm en dos nuevas organizaciones. Buena parte de la militancia polimili, aquellos que tenían un perfil más político o sindical, y de los presos recién amnistiados pasaron al interior de España para preparar el partido ${ }^{75}$. Estos militantes, que dejaban ipso facto de pertenecer a ETApm, convergieron con simpatizantes e independientes para formar el primer embrión del partido, es decir, el reagrupamiento.

69. «Informe a la militancia (interno)», en Documentos Y, vol. XVIII, pp. 497-499.

70. «La crisis y escisión en ETA (p-m)», Hautsi, 15 (julio 1977).

71. Likiniano Elkartea, Komando Autonomoak: sasiaren arantzakada. Una historia anticapitalista, Bilbao, 1999.

72. «ETA berrantolatzen ari», Egin, 29 de septiembre de 1977.

73. Ugarte, Ángel y Medina, Francisco, Espía en..., p. 231.

74. Entrevista a Iñaki Martínez, Bilbao, 10 de marzo de 2007.

75. Entrevista a Joseba Aulestia, cit. 
La dirección de ETApm designó directamente a la del partido (el Comité Ejecutivo provisional). Escogió lo más parecido a políticos que tenía a su alcance, «legales» (no fichados por la policía) relacionados con las organizaciones de masas abertzales: Iñaki Martínez, Joseba Knörr, José Luis Alustiza, Martín Auzmendi, Andoni Azkue, Iñaki Maneros, Gregorio López Irasuegui, etc. Durante meses se dedicaron a recorrer pueblos y barrios para coordinar las denominadas «mesas de reagrupamiento» que se reunían para debatir el proyecto de Pertur ${ }^{76}$. Como recuerda Iñaki Martínez, «encontramos un apoyo que no creíamos que iba a existir. Salían mesas de reagrupamiento por todas las esquinas» ${ }^{77}$. Pronto se convirtieron en los comités locales del partido.

Gracias a la tolerancia del Gobierno, EIA se presentó públicamente el 3 de abril de 1977 en el frontón de Gallarta, lugar escogido por ser la cuna del movimiento obrero vizcaíno y el pueblo natal de Dolores Ibárruri (Pasionaria). El acto permitió visualizar las contradicciones simbólico-ideológicas de EIA. Por una parte, se repartió el Manifiesto del partido, que estaba tan empapado de marxismo-leninismo como las elaboraciones teóricas anteriores ${ }^{78}$. Por otra, en un escenario, repleto de carteles con la efigie de Pertur, hablaron las madres de dos polimilis muertos por la policía, se escuchó una grabación de Ezkerra y Wilson y se leyó un comunicado de apoyo de ETApm. Por si quedaban dudas, Gregorio López Irasuegui afirmó que «es cierto que no somos ETA, pero esa separación no significa un abandono de los ideales por los que ETA luchó durante quince años. Nosotros continuaremos la lucha de otra manera. Ellos seguirán la lucha armada, nosotros mantendremos la lucha política» ${ }^{79}$.

A Mario Onaindía, futuro secretario general de EIA, la presentación le pareció decepcionante. Se esperaba más de un «partido con vocación de "vanguardia"» que «limitarse a homenajear a los etarras muertos y presos» ${ }^{80}$. La proliferación de símbolos vinculados a ETA no se correspondía para nada con el partido leninista que EIA pretendía ser en sus documentos. La razón última estribaba en que, como recuerda Iñaki Martínez, sólo una minoría de los militantes era realmente comunista. «Pero los demás éramos revolucionarios. Revolucionarios en el sentido de que queríamos hacer la revolución de verdad. Pero no leninistas. Éramos más nacionalistas que otra cosa» ${ }^{81}$. Un grupo de militantes lo resumía perfecta-

76. Arnasa, 1 (1976).

77. Entrevista a Iñaki Martínez, cit.

78. «Manifiesto de presentación de EIA. A la clase obrera y a todo el pueblo de Euskadi», 1977.

79. «EIA, un partido esencialmente obrero», El País, 3 de abril de 1977.

80. Onaindía, Mario, El precio de la libertad. Memorias (1948-1977), Madrid, 2001, p. 607.

81. Entrevista a Iñaki Martínez, cit. 
mente: «la mayoría de la base de EIA (...) la constituimos elementos que han sido en estos últimos años, simplemente incondicionales de ETA y carecíamos de una mayor formación política» ${ }^{82}$.

Resultaba evidente que EIA era una creación de ETApm en todos los sentidos. Incluso en su iconografía, ya que la ikurriña con forma de puño que aparecía en la portada de los Hautsi de ETApm desde septiembre de $1975^{83}$ pasó por la del Arnasa n. ${ }^{\circ} 1$ y la del Manifiesto hasta convertirse en el símbolo de EIA.

Al menos durante esta primera fase de la historia del partido, EIA era «casi el brazo político de ETApm ${ }^{84}$ o, como poco, se daba por sentado «cierto dirigismo desde ETApm $»^{85}$. La influencia polimili era tan evidente que produjo el rechazo de algunos de los futuros líderes de EIA, que no quisieron acercarse al partido en ese momento ${ }^{86}$. La situación no cambió hasta la primera Asamblea de EIA, en octubre de 1977, cuando se eligió democráticamente a Mario Onaindía como cabeza de un nuevo Comité Ejecutivo, momento en el que el partido alcanzó la suficiente autoridad y autonomía como para ir tomando decisiones independientes. Sólo entonces ETApm se convirtió en la fiel retaguardia. Y, aunque las decisiones importantes se tomaban globalmente, en las periódicas reuniones de coordinación, por lo general era EIA la que marcaba la dirección política ${ }^{87}$.

Otra de las contradicciones del partido era su organización interna. A pesar de defender el centralismo democrático, EIA estaba muy lejos de la organización de un partido bolchevique. Según su dirección, se parecía «más a un conjunto de miniasambleas populares que a un partido ${ }^{88}$. Sin embargo, había una dedicación plena, «como la militancia en ETA, estábamos 24 horas $»^{89}$. Nadie cobraba del partido, no hubo liberados hasta después de las primeras elecciones. EIA se financiaba a través de sus militantes, de préstamos y de las donaciones de ETApm que fueron una de las principales fuentes de ingresos del partido hasta $1982^{90}$.

EIA presentó sus estatutos en el Gobierno Civil de Pamplona pero fue declarado ilegal por manifestar como objetivos la independencia de Euskadi y la

82. «Mesa de EIA de San Juan en torno a las elecciones», Boletín interno de EIA, 5 (julio 1977).

83. Véase la portada del Hautsi, 6 (septiembre 1975).

84. Entrevista a Iñaki Martínez, cit.

85. Entrevista a Francisco Letamendia, Lejona, 28 de febrero de 2007.

86. Entrevista a José Manuel Ruiz, Bilbao, 8 de julio de 2008.

87. Entrevista a Fernando López Castillo, Bilbao, 19 de febrero de 2007.

88. «EIA ante las elecciones», 1977.

89. Entrevista a Luis Emaldi, Vitoria, 2 de marzo de 2007.

90. Entrevista a Goio Baldus, Bilbao, 19 de junio de 2009. 
revolución socialista ${ }^{91}$. A principios de 1978 modificó sus objetivos y fue legalizado ${ }^{92}$.

\section{La crisis de KAS}

Pertur había escrito que el partido debía participar en las elecciones, pero las dudas persistieron entre sus seguidores. En el referéndum de la Ley para la Reforma Política del 15 de diciembre de 1976, los polimilis propugnaron la abstención y la huelga general, pero el éxito de Suárez les llevó a admitir que el pueblo vasco estaba a favor de la democracia parlamentaria93. Como ya se ha explicado, los gestos del Gobierno consiguieron vencer las últimas resistencias internas, aunque la mayoría de la dirección provisional de EIA tenía clara su postura desde el principio: «la única condición que pondríamos por nuestra parte era la de que nos dejen participar (...) y nada más $»^{94}$.

Sin embargo, el resto de KAS no opinaba lo mismo. Al principio ETAm, LAIA y EHAS se opusieron a participar, pero luego defendieron la «participación condicionada al cumplimiento por parte del Gobierno de dos condiciones: Libertades democráticas, Amnistía» ${ }^{95}$. La Koordinadora se dividió en dos bloques antagónicos, aunque finalmente consiguieron llegar al compromiso de que EIA aceptaba temporalmente las condiciones y el resto le ayudaba a levantar una coalición ${ }^{96}$. Sin embargo, ni ETAm tenía intención de formar parte en un proceso que le podía condenar a renunciar a «la lucha armada», ni EIA a supeditarse a las decisiones de las otras organizaciones ${ }^{97}$.

Si EIA continuó en KAS fue sólo para defenderse de las presiones externas e internas y evitar ser acusada de romper el mito de la «unidad abertzale $»^{98}$. De igual manera hay que analizar su participación en la Cumbre de Chiberta (Francia, abril-mayo de 1977) auspiciada por Telesforo Monzón, en la que ETAm intentó convencer infructuosamente al PNV de que se uniera al boicot a las elecciones ${ }^{99}$. Tanto el PNV como el resto de la oposición ya habían apostado firmemente por la participación ${ }^{100}$.

91. «La solicitud de KAS», Punto y Hora de Euskal Herria, 35 (12-18 mayo 1977).

92. «El ministerio del Interior legaliza a EIA», El País, 19 de enero de 1978.

93. «Sobre política electoral», Kemen, 10 (marzo 1977).

94. «El partido ante las elecciones», febrero de 1977, Kemen, 10 (marzo 1977).

95. «Sobre política electoral», Kemen, 10 (marzo 1977).

96. «Informe sobre los debates de KAS. Las razones de EHAS», junio de 1977.

97. Fernández Soldevilla, Gaizka, «El nacionalismo vasco radical ante la Transición española», Historia Contemporánea, 35 (2007), pp. 817-844.

98. Entrevista a Iñaki Martínez, cit.

99. Fernández Soldevilla, Gaizka, «Ellos y nosotros. La Cumbre de Chiberta y otros intentos de crear un frente abertzale en la Transición», Historia del Presente, 13 (2009), pp. 97-114.

100. Para la historia del PNV durante el franquismo y la Transición, véase Pablo, Santiago de, Mees, Ludger y Rodríguez Ranz, José Antonio, El péndulo patriótico. Historia del Partido 
El presidente Adolfo Suárez, aconsejado por el abogado Juan María Bandrés, fue el que le dio el argumento final a EIA ${ }^{101}$. El Gobierno del 20 de mayo, a pesar de la firme oposición del ministro del Ejército, decidió aplicar el extrañamiento a los presos más prestigiosos de ETA, como Mario Onaindía y Eduardo Uriarte $(\mathrm{Teo})^{102}$. EIA consideró que se había concedido la amnistía y el 29 de mayo celebró una Asamblea extraordinaria en Beasain (Guipúzcoa) donde sus militantes aprobaron mayoritariamente la participación ${ }^{103}$. Esa decisión le costó la defección de la mayoría de sus integrantes en Navarra ${ }^{104}$ y una grave crisis con el resto de KAS. Para ETAm, «la amnistía total no significa en nada extrañamiento (...). Si para el 24 podemos poner patas arriba Euskadi, lo pondremos» ${ }^{105}$.

\section{La primera Euskadiko Ezkerra}

EIA no podía concurrir en solitario a las elecciones ya que carecía de experiencia, organización e infraestructura. Por esa razón se decantó por formar «una alianza de izquierda vasca» en la que se incluyera a todos los partidos a la izquierda del PCE ${ }^{106}$. El EEH le sirvió para retomar los contactos que Pertur había tenido con el MCE, denominado EMK (Movimiento Comunista de Euskadi) en el País Vasco. Se trataba de una organización consolidada, con una fuerte infraestructura e implantación y que, además, tenía como idea fundacional la unidad de la clase obrera vasca por encima de las identidades nacionales ${ }^{107}$.

A principios de marzo de 1977 el EMK envió una carta a KAS ofreciéndose como aliado para «una candidatura única» ${ }^{108}$. EIA recogió la invitación. En realidad la idea era formar una candidatura abierta a toda la izquierda vasca, y es cierto que a las reuniones preparatorias asistieron muchos partidos, tanto de la extrema izquierda como de KAS, pero todos las abandonaron hasta quedar únicamente EIA y EMK ${ }^{109}$, con el apoyo externo de Eusko Sozialistak. La coalición se llamó Euskadiko Ezkerra (Izquierda de Euskadi), un nombre propuesto por el propio EMK ${ }^{110}$, pero no era toda la izquierda de Euskadi. Se trataba de la candi-

Nacionalista Vasco, II. 1936-1979, Barcelona, 2001.

101. Castro, Raúl, Juan María Bandrés. Memorias para la paz, Madrid, 1998, pp. 145-148.

102. Abella, Carlos, Adolfo Suárez. El hombre clave de la Transición, Madrid, 2006, p. 268.

103. «EIA (Partido para la Revolución Vasca) irá a las elecciones», El País, 31 de mayo de 1977.

104. «EIA, Navarra y las elecciones», junio de 1977, Boletín interno de EIA, 3 (agosto 1977).

105. «Reunión del KAS», 22 de mayo de 1977, Boletín interno de EIA, 5 (agosto 1977).

106. «Los partidos se definen», Garaia, 24 (10-17 febrero 1977).

107. Entrevista a Josetxo Fagoaga, San Sebastián, 23 de febrero de 2007.

108. «A las fuerzas del KAS», 5 de marzo de 1977, Kemen, 10 (marzo 1977).

109. «EIA ante las elecciones», 1977.

110. Entrevista a Iñaki Martínez, cit. 
datura legal (una agrupación de electores) de dos partidos ilegales y un puñado de independientes.

Para el EMK la alianza con EIA representaba la materialización de su proyecto de construir un puente con el nacionalismo radical ${ }^{111}$, por lo que se planteó EE como un proyecto a largo plazo ${ }^{112}$. Sin embargo, la dirección de EIA era consciente de que su popularidad, heredada de ETA, le iba a permitir «poner los votos», pero necesitaba que el EMK «le hiciese la campaña electoral». En definitiva, EIA «instrumentalizó deliberadamente» al EMK ${ }^{113}$. La alianza de dos culturas políticas tan diferentes respondía al simple pragmatismo, por lo que no extraña que John Sullivan definiese a esta primera EE como un «matrimonio de conveniencia» ${ }^{114}$.

El programa consensuado con el que EE se presentó a las elecciones era moderado y posibilista tanto en el aspecto nacional como en el socioeconómico. Si en el primero defendía la promulgación inmediata de un Estatuto de autonomía, en el segundo proponía algunas reformas que no cuestionaban el sistema capitalista ${ }^{115}$, lo que muestra el esfuerzo de EIA y el EMK para atraer a más potenciales votantes.

El caso de Navarra fue diferente, ya que la relación de fuerzas no era la misma que en el País Vasco. EIA era un partido muy débil, lo que permitió al EMK imponer que en esa provincia no se presentase EE sino UNAI, Unión Navarra de Izquierdas, lo que para los abertzales significaba romper la unidad nacional de Euskadi. EIA de Navarra, en plena crisis tras la Asamblea de Beasain, se negó a apoyar a UNAI y la mayoría de sus miembros salió del partido ${ }^{116}$.

\section{Las elecciones del 15 de junio de 1977}

EHAS, LAIA, ETAm y los Komando Bereziak no hicieron una campaña intensa a favor de la abstención, aunque consiguieron el apoyo simbólico de ex presos de ETA $^{117}$ y de la Gestora pro Amnistía de Guipúzcoa ${ }^{118}$, así como la retirada de las listas de EE de algunos candidatos ${ }^{119}$. ETAm, que perpetró treinta y cuatro pequeños atentados ${ }^{120}$, publicó un manifiesto propugnando la abstención, al

111. «Bajo la bandera de la unidad», Zer egin?, 26 (primera quincena febrero 1978).

112. Entrevista a Javier Villanueva, Guernica, 9 de marzo de 2007.

113. Entrevista a Iñaki Martínez, cit.

114. Sullivan, John, El nacionalismo vasco radical, 1959-1986, Madrid, 1988, p. 218.

115. «Programa electoral de Euskadiko Ezkerra», 1977.

116. Entrevista a Bixente Serrano Izko, Pamplona, 17 de enero de 2009.

117. «Ex presos políticos vascos propugnan el boicot activo», El País, 8 de junio de 1977.

118. «La gestora por Guipúzcoa boicotea las elecciones», El País, 5 de junio de 1977.

119. «Ocho candidatos abertzales ratifican su retirada de las elecciones», El País, 4 de junio de 1977.

120. «Acciones pre-electorales», Zutik, 68 (julio 1977). 
igual que los berezis. ETApm hizo lo propio a favor de la participación ${ }^{121}$, aunque fue mucho más efectivo el apoyo público que EIA consiguió de algunos de los extrañados, como Jokin Gorostidi, Xavier Larena, Mario Onaindía y Teo Uriarte, que se habían convertido en auténticos héroes abertzales tras el proceso de Burgos (1970) 122 .

El EMK cumplió lo que se esperaba de él gracias al trabajo de su militancia. La campaña electoral que llevó a buen puerto fue ambiciosa. Por poner un ejemplo, sólo en Vizcaya se celebraron 34 mítines, que se llenaron de público ${ }^{123}$. Según sus organizadores, el mitin-festival de la Feria de Muestras de Bilbao del 12 de junio reunió entre treinta y cuarenta mil personas ${ }^{124}$. Se financió «pasando la boina $»^{125}$ y con el esfuerzo abnegado de cientos de voluntarios, incluyendo a profesionales que trabajaron gratuitamente para EE, como el dibujante Juan Carlos Eguillor o los cantantes Gorka Knörr, Oskorri, Urko, Miren Aramburu, los Hermanos Loroño, Luis Pastor, etc. ${ }^{126}$ El EMK, además, editó cuatro números de un periódico bajo la cabecera de Euskadiko Ezkerra, que se agotaron.

EIA no pasó de pedalear sin mucho entusiasmo «chupando rueda» al EMK ${ }^{127}$. Tampoco su campaña electoral fue demasiado efectiva, ya que carecía de experiencia a todos los niveles ${ }^{128}$. Además, los roces entre EIA y el EMK, producto del sectarismo y la rivalidad, fueron constantes por ambas partes ${ }^{129}$.

Los resultados de las elecciones del 15 de junio de 1977 demostraron que la ciudadanía vasca había apostado por la moderación y la autonomía ${ }^{130}$. El índice de abstención en el País Vasco fue de un 22,7\%, sólo ligeramente superior a la media española $(21,1 \%)$. El PNV obtuvo el $29,28 \%$ de los votos y ocho diputados, el PSOE el 26,48\% y siete, UCD el 12,81\% y cuatro, AP el 7,11\% y uno. No conseguían representación alguna el PCE, la extrema izquierda ni el resto del

121. Los tres comunicados en Boletín interno de EIA, 5 (julio 1977).

122. "Volver a casa a través de Bélgica», Punto y Hora de Euskal Herria, 38 (2-8 junio 1977).

123. «Euskadiko Ezkerra: un testigo molesto», Servir al pueblo, 78 (4 junio 1977).

124. «Los luchadores del pueblo vasco con Euskadiko Ezkerra», Servir al pueblo, 79 (20 junio 1977).

125. Entrevista a Javier Villanueva, cit.

126. «Apoyan a EE», Euskadiko Ezkerra, 4 (junio 1977).

127. «Acta de la Mesa Nacional», 26 de junio de 1977, Boletín interno de EIA, 3 (agosto 1977)

128. «Balance y crítica de lo que ha supuesto tanto el proceso en general como la campaña electoral de la Mesa de Intxaurrondo», Boletín interno de EIA, 5 (agosto 1977).

129. Entrevista a Javier Villanueva, cit.

130. Pérez Ares, María Isabel, «Las primeras elecciones democráticas en el País Vasco», en Capellán, Gonzalo y Pérez Serrano, Julio (eds.), Sociedad de masas, medios de comunicación y opinión pública, Logroño, 2008, vol. I, pp. 135-150. 
nacionalismo vasco. El 6,07\% de los ciudadanos (61.417) ${ }^{131}$ votaron a Euskadiko Ezkerra, la quinta fuerza más votada, que pudo colocar en las Cortes a dos de los abogados del proceso de Burgos: Francisco Letamendia (Ortzi) como diputado y Juan María Bandrés como senador ${ }^{132}$. Ambos visitaron las tumbas de los mártires de ETApm Txiki y Otaegui para jurar ritualmente «seguir luchando hasta las últimas consecuencias por los mismos objetivos por los cuales ellos habían muerto», lo que suponía reclamar una vez más la herencia de ETA a través de sus símbolos ${ }^{133}$.

En Navarra la UCD de Suárez, con tres diputados, se convertía en la primera fuerza política, seguida por el PSOE, con dos. UNAI, la tercera candidatura más votada, se quedaba, con 24.489, a unos cientos de votos de lograr un acta.

EIA creyó que podía, por fin, convertirse en el partido dirigente que había teorizado Pertur y arrastrar tras de sí a los restos derrotados de $\mathrm{KAS}^{134}$. Por otro lado, para EIA el EMK ya había cumplido su papel. Euskadiko Ezkerra era un «compromiso electoral»y no «una alianza política» ${ }^{135}$. La tormentosa relación entre EIA y el EMK terminó en febrero de 1978, cuando este último, continuamente marginado, abandonó EE. Desde ese momento y hasta su convergencia con el EPK (Partido Comunista de Euskadi) de Roberto Lertxundi en 1982, EE se limitó a ser el frente electoral de EIA.

También ETApm se felicitó por los resultados de EE y asumió públicamente que «a partir de este momento, el poder dispone de una legitimidad completamente diferente de la que poseía hasta ahora: si antes se basaba exclusivamente en la fuerza, hoy esa legitimidad le viene del sufragio popular» ${ }^{136}$. Para los polimilis, comenzaba la lógica de la retaguardia. Para EIA, el papel de vanguardia dirigente.

Los milis culparon a ETApm y EIA del fracaso del boicot a las elecciones y de la crisis de la izquierda abertzale ${ }^{137}$. ETAm se negó a aceptar que había habido un cambio ya que el sistema era «una dictadura militar encubierta por un parla-

131. Ministerio Del Interior, «Base histórica de resultados electorales», http://www.elecciones.mir.es.

132. También se habían convertido en héroes populares. Personas por entonces tan lejanas ideológicamente a Bandrés, como Ramón Jáuregui, estudiaron Derecho para emularle. Entrevista a Ramón Jáuregui, Madrid, 3 de noviembre de 2008.

133. «Euskal Iraultzarako Alderdia», julio? de 1977.

134. «Sobre la política de alianzas a desarrollar por el partido», 29 de junio de 1977, Boletín interno de EIA, 2 (junio 1977).

135. «Comunicado de EIA en torno a las declaraciones de Rosa Olivares en TV sobre la muerte de Ibarra», Boletín interno de EIA, 3 (agosto 1977).

136. «Introducción», Hautsi, 15 (julio 1977).

137. «La evolución de la organización PM y sus consecuencias en EIA», Zutik, 68 (julio 1977). 
mento completamente domesticado» ${ }^{138}$. Desde finales de 1977 , fortalecida por la unificación con los berezis, la organización terrorista se fijó el objetivo de obligar al gobierno Suárez a aceptar la alternativa táctica KAS.

HASI, LAIA y otros dos partidos nacionalistas de centro-izquierda formaron la coalición Herri Batasuna (Unidad Popular) para competir con EE. ETAm renunció definitivamente a su automarginación de la lucha política y tomó el control de HASI, tras lo cual la mayoría de los que habían sido sus líderes pasó a EIA $^{139}$. ETAm se convirtió en la organización dirigente, HASI en su brazo político y $\mathrm{HB}$ en su frente electoral ${ }^{140}$, es decir, una copia invertida de la relación entre EIA, EE y ETApm.

La división de 1974 entre milis y polimilis se trasladó a las organizaciones políticas y sociales convirtiéndose en la ruptura definitiva del nacionalismo vasco radical. Comenzó una dura disputa por la herencia compartida entre dos bandos irreconciliables: el posibilista y el maximalista. ETAm y sus aliados arrebataron a EIA la herencia de ETA. Primero, a finales de 1977, EIA fue expulsado de KAS, bajo la acusación de haber roto la mítica «unidad abertzale». Al año siguiente sus militantes y simpatizantes fueron despedidos de los medios de comunicación (Egin, Punto y Hora de Euskal Herria) y marginados de organizaciones de masas, como el sindicato $\mathrm{LAB}^{141}$, que en la mayoría de los casos había creado la propia ETApm. La izquierda abertzale radical consiguió así conformar un movimiento o comunidad que giraba en torno a ETAm ${ }^{142}$. Mientras tanto HB arrebataba a EIA el protagonismo en las movilizaciones, la bandera de la amnistía, el discurso radical, la vinculación con la «auténtica» (más mortífera) ETA, etc. Por poner un ejemplo en el plano simbólico, que resulta muy significativo, en 1979 el hermano de Txiki, alineado con HB, denunció a EIA por haber «traicionado a todos los muertos habidos hasta ahora desde la guerra del $36 »^{143}$. Paralelamente, los simpatizantes de Herri Batasuna se dedicaron a reventar los actos en los que los de EIA conmemoraban el fusilamiento de los polimilis Txiki y Otaegi ${ }^{144}$. La presión de los radicales consiguió su objetivo: desde 1979, el 27 de septiembre,

138. «La oligarquía española en Euskadi ante las elecciones», Zutik, 68 (julio 1977).

139. Casanova, Iker y Asensio, Paue, Argala, Tafalla, 1999, pp. 299 y 300.

140. Sullivan, John, El nacionalismo..., p. 228.

141. En el caso de LAB el continuo enfrentamiento entre partidarios de HASI y de EIA hizo tan inoperante al sindicato que la dirección de EIA decidió sacar a sus afiliados para entrar en ELA.

142. Mata López, José Manuel, El nacionalismo vasco radical. Discurso, organización y expresiones, Bilbao, 1993.

143. Paredes, Mikel, "Al "viento de libertad" no lo detiene un estatuto», Egin, 23 de septiembre de 1979.

144. «Lo sucedido en Zarauz», Hitz, 2 (septiembre 1979). 
bautizado como Gudari Eguna (Día del Soldado Vasco), fue monopolizado por HB y su entorno ${ }^{145}$. Se trata de un claro caso de vampirización de símbolos.

Las últimas dudas sobre quién se quedaba con la mayor parte de la herencia de ETA se despejaron en las elecciones generales de marzo de 1979, en las que, con el apoyo explícito de ETAm, HB consiguió 149.685 votos frente a los 80.098 de EE.

\section{Conclusiones}

Pertur intentó adaptar la izquierda abertzale a la democracia mediante la creación de un partido-dirigente de corte bolchevique y el paso de ETApm a la retaguardia defensiva. El partido debía aliarse con la extrema izquierda, formar una coalición amplia y presentarse a las elecciones; en otras palabras, asumir la llegada de la democracia y participar en ella, aunque fuese sólo como un instrumento para la revolución. Estas ideas, una auténtica renovación teórica y estratégica para ETA, motivaron la crisis de la organización político-militar, la escisión de los berezis y quizá también la muerte del propio Pertur.

EIA fue una creación de ETApm en todos los sentidos (teoría, estrategia, símbolos, militancia, financiación, etc.). También en sus contradicciones ideológicas, su rivalidad con ETAm y en la interdependencia que permite definir a la EIA de 1977 como el brazo político de ETApm. Por otra parte, el partido heredó los contactos con el gobierno Suárez, que le aseguraron las condiciones mínimas para poder presentarse a las elecciones: tolerancia y extrañamientos. Por último, también era polimili la política de alianzas que llevó a EIA a formar con el EMK una candidatura denominada Euskadiko Ezkerra.

Este plan de actuación, al igual que la teoría plasmada en los documentos oficiales de ETApm y EIA, tenía un fuerte contenido marxista-leninista. Pero ésta, si bien importante, no es la única clave a tener en cuenta, ya que no permite una explicación satisfactoria de los orígenes de EE. La mayoría de los militantes y simpatizantes de EIA, como se ha visto, no compartían la cultura política comunista de algunos de sus dirigentes. Eran nacionalistas radicales, «simplemente incondicionales de ETA», y todo su universo ideológico provenía de esa organización: héroes como los presos del Proceso de Burgos, mártires como Txiki y Otaegi, fundador como Pertur, consignas movilizadoras como la amnistía, etc. EIA buscó vincularse simbólicamente a ETA para heredar sus adhesiones emocionales, y fue esta popularidad transferida la que le proporcionó los votos suficientes para obtener dos parlamentarios y asegurarse la supervivencia política, lo

145. Sobre el Gudari Eguna, véase CASQuete, Jesús, En el nombre..., pp. 179-217. 
que no consiguieron ni la extrema izquierda ni el resto del nacionalismo vasco, salvo el PNV.

En 1977 EIA tenía aparentemente los recursos para haber llegado a ser el núcleo sobre el que se creara tanto una «religión política» abertzale como un «partido-comunidad», como luego ocurrió con sus competidores. Sin embargo, para 1979, como ya se ha referido, HB-ETAm había arrebatado a EIA-EE la mayor parte de la herencia de ETA, su universo simbólico y el control de la comunidad abertzale que estaba en proceso de formación, frustrando esa posibilidad. Una de las claves para explicar esto es sencilla. EIA, dirigida desde octubre de 1977 por Mario Onaindía, renunció conscientemente a tomar ese camino. Su evolución le alejaba paulatinamente del nacionalismo radical de sus orígenes y le acercaba al posibilismo y a la vía institucional que abrazó por completo cuando apoyó el Estatuto de Guernica. Fue un proceso largo y dificultoso, que incluyó la renuncia al plan de Pertur y la secularización de los restos «religiosos» que le quedaban, y que culminó en 1982 con el abandono de las armas por ETApm y la convergencia de EIA y el EPK para dar lugar al partido Euskadiko EzkerraIzquierda para el Socialismo. 